How to cite this article:

Kashim, R., Kasim, M. M., \& Rahman, A. R. (2018). Measuring efficiency of a university faculty using a hierarchical network data envelopment analysis model. Journal of Information and Communication Technology, 17(4), 569-585.

\title{
MEASURING EFFICIENCY OF A UNIVERSITY FACULTY USING A HIERARCHICAL NETWORK DATA ENVELOPMENT ANALYSIS MODEL
}

\author{
Rosmaini Kashim, Maznah Mat Kasim \& Rosshairy Abd Rahman \\ School of Quantitative Sciences \\ Universiti Utara Malaysia, Malaysia
}

rosmaini@uum.edu.my;maznah@uum.edu.my; shairy@uum.edu.my

\begin{abstract}
An efficiency measurement model of a university faculty is proposed with additional new sub-functions that produce new output variables, based on the network Data Envelopment Analysis (DEA) model for systems with a hierarchical structure. For production systems composed of hierarchical processes, the system efficiency is well represented as the aggregated performance of the components involved in the system. It is identified that the conventional DEA model ignores internal process activities in a university. Therefore, an improved DEA model based on a network structure that accounts for more activities in a university is proposed to measure its overall efficiency. The impact of major functions of a university are taken into account to represent the output variables in assessing the efficiency. Currently, collaboration activities have been given more attention, so, this variable is suggested as a new output for the hierarchical production system. In order to show the practicality of the model, a hypothetical set of data of 14 faculties has been used as a numerical example. The results show that none of the faculties is relatively efficient since its functions were found to be inefficient. The proposed model enables to help
\end{abstract}


the management of university faculties to identify weaknesses of each function and thus to plan for suitable actions on improving the overall performance of the university.

Keywords: Data envelopment analysis, efficiency measurement model, hierarchy structure, network model.

\section{INTRODUCTION}

A measurement of operational efficiency plays an important role in evaluating the capability of an organization in transforming resources or inputs to outputs to the optimum level. Efficiency measurement is not only giving information about the past accomplishments of a unit, but it also identifies the projections for improvement for future development (Kao, 2017). Assessment of efficiency should be applied to all business sectors, including the education sector. Currently, the number of Institutions of Higher Learniabsng (IHL), especially the private IHL increases dramatically. Thus, the public IHL must be competitive to produce knowledgeable and competitive enough students to further enhance economic and national development. Therefore, measuring the resources efficiency of a faculty in a university needs to be done to ensure that the faculty will utilize allocated resources efficiently in producing quality graduates and high-quality researches (Wan Husain, 2012).

Various methodological approaches have been used to resolve this efficiency measurement issue. One study by Johnes (2006) used regression analysis, while a study by Izadi (2002) utilized the two parametric approaches, the Stochastic Frontier Analysis (SFA) and Multiple Regression Analysis (MRA). However, the most popular and favoured method by today's researchers to measure the performance or more specifically the efficiency of universities is the non-parametric approach, Data Envelopment Analysis (DEA) (Grosskopf, Hayes, \& Taylor, 2014; Huguenin, 2015; Avilés, Güemes, Cook, \& Cantú, 2015; De Witte \& Rogge, 2011). As a linear programming technique (Johnes, 2006, Johnes, 2015), the DEA results are not difficult to interpret as compared to other methods since the DEA efficiency scores are derived based on the specific inputs and outputs data (Abdullah, KuMahamud, Ahmad, Ghani, \& Kasim, 2012; Collier et al., 2011). The DEA is a suitable method to be used in assessing the efficiency of an organization that uses multiple inputs and produces multiple output. Previous studies that used the DEA method for measuring the efficiency of universities in Malaysia are Alwadood et al. (2011), Wan Husain (2012) and Ismail et al. (2014). In addition, Johnes and Yu (2008) have used four DEA models to a sample of 
top 109 higher education institutions in China to measure efficiency of the institutions in producing research. In another study by Kao and Hung (2008), the DEA was used to assess the relative efficiency of over 41 departments at National Cheng Kung University in Taiwan. However, all the studies used the single-stage type DEA models. Conventional DEA models do not consider internal structure of decision making units (DMUs) (Kao, 2015; Gua et al., 2017). While in the real world, organizations have various structures such as two-stage structure, parallel structure and hierarchical structure. Therefore, in order to provide a more meaningful efficiency measures, the internal structure of a system must be taken into account in the evaluation model (Kao, 2015). Most of the researches focused on one function of the university (Johnes \& Yu, 2008; Kao \& Hung, 2008; Ahmi \& Mohamad, 2016; Kasim et al., 2017), or combined all the functions of the university to form a single-stage DEA model (Alwadood et al., 2011; Wan Husain, 2012; Ismail et al., 2014). When these models were applied to a university, the internal activities in each function of the university were ignored. This will make it difficult for the university to accurately determine the influence of the individual inefficiencies of teaching, research and community services on the overall efficiency of the university (Monfared \& Safi, 2013).

Thus, the hierarchal structure is suitable to be applied to universities since the organizational structure of universities has more than two functions or components. The faculties usually have three main functions, teaching, research and community service in meeting the requirements of the university. A recent study conducted by Kao (2015) has used the hierarchical structure to measure the efficiency of the Department of Physics at a university. Kao's study can be extended to the faculty system in Malaysia's universities. Therefore, in this study, Kao's hierarchical system is applied and extended in Malaysian universities where the teaching function was further divided into three activities, namely activities of teaching undergraduate, masters and $\mathrm{PhD}$ students. While, service to the community can be further divided into consultation activities and cooperation activities. Apart from teaching and research, the faculty is also expected to provide services to the community and this can be done in two ways, one is to assist local businesses in the research and development activities and became a consultant to solve problems at their company, and second is to offer a course or workshop to the local communities who need advanced programs (Tumuti et al., 2013). Meanwhile, the cooperation of the university with industry is a worldwide practice now and is going to be a feature of lifelong learning at the university (Dan, 2013; Tumuti et al., 2013). Thus, consultation and collaboration activities are proposed as new internal processes and should be taken into account in the measurement of the efficiency of the faculty. 
Therefore, the aim of this paper is to propose a model in measuring the efficiency of a university faculty without neglecting its internal structure based on the network DEA model for systems with a hierarchical structure. This paper is presented in seven sections. In the second and third section, efficiency measurement approaches and DEA are discussed further. The data and the hierarchical structure are discussed in fourth section. The fifth section contains the proposed model for measuring efficiency of a university faculty. Next, the application of the model to measure efficiency of 14 hypothetical university faculties is discussed. The final section provides the conclusions of this research work.

\section{EFFICIENCY MEASUREMENT APPROACHES}

Different techniques and approaches can be used to measure efficiency. Two main classes of methods are parametric and non-parametric (Cordero-Ferrera, Pedraja-Chaparro, \& Salinas-Jiménez, 2008), and the appropriateness of the method depends heavily on the level of data used in the analysis. Preliminary studies on performance of IHLs using regression analysis show that large interuniversity variations in every output measure such as student completion rates, grades and successes of the labour market graduates were clarified by similar variations in a small number of input variables. Furthermore, Johnes (1996; 2006) concluded that the regression analysis approach is not suitable to be used in the education sector since educational institutions use multiple inputs to produce multiple outputs, while any performance indicator constructed using regression model is derived from a production function that is the average line through data rather than frontiers around the data. Another parametric frontier approaches such as SFA and non-parametric DEA are introduced to address this problem. The SFA proposed by Aigner, Lovell, and Schmidt (1977) usually uses a stochastic process to measure the efficiency, where the output of DMU below the valuation is a function of multiple inputs (Coelli et al., 2005). However, SFA has a major limitation where it imposes an explicit functional form and statistical distribution on empirical data (Worthington, 2001). Therefore, the SFA has also been considered as an improper approach to assess the efficiency of IHL. In other literature, some studies used both parametric and non-parametric techniques for a specific sample by comparing efficiency scores generated by the two methods (Bates, 1997; Chakraborty et al., 2001; Mizala et al., 2002). In Yu's study (1998) Monte Carlo experiments were used where the underlying production technology is known. Nevertheless, most researchers (Grosskopf, Hayes \&Taylor, 2014; Huguenin, 2015; Avilés, Güemes, Cook, \& Cantú, 2015) use nonparametric approximations and, 
specifically, DEA to measure efficiency in educational sector. One of the main reasons of the selection of DEA is due to its high flexibility and suitability in the educational sector where the production function is not known besides its ability to adapt to processes involving not only a range of inputs but also a series of intermediate outputs, rather than a single final input (Seiford \& Thrall, 1990; Cook \& Seiford, 2009).

\section{DATA ENVELOPMENT ANALYSIS}

DEA is a non-parametric approach introduced by Charnes et al. (1978) which is based on the linear programming techniques. DEA has been widely used as an effective technique for measuring the relative efficiency of a set of DMUs using multiple inputs to produce multiple outputs (Ku-Mahamud, Kasim, Abd.Ghani \& Abdullah, 2011; Liu et al., 2013). The most basic DEA model is known as Charnes-Cooper-Rhodes (CCR) model (Charnes et al., 1978) and is treated as a black box (or single-stage DEA) model, where only inputs are supplied to and the output produced from the box is taken into account otherwise the operation and interdependence of internal processes are ignored. As a result, the system can be assessed as efficient even though all component processes are not (Castelli et al., 2004). In order to get more accurate efficiency measures, the internal structure of a system must thus be considered whenever the data is available. Thus, the network DEA has been introduced by Färe \& Grosskopf (2000) where this approach takes all operations of the process components into consideration under the framework of DEA. Many studies have explored the internal process of the DEA model and the systems can have several structures such as two-stage, parallel, hierarchical, series and multistage (Kao, 2015). However, hierarchical systems have attracted relatively little attention, even though almost all organizations have a hierarchical structure (Kao, 2015). Organizations usually have several units at the first level, so several subunits are set up at the second level. Possibility, large subunits are further divided into several sub-subunits with different functions at the third level, and the next level can be continued if necessary. Besides that, the network DEA model is less flexible than the basic CCR model (or black box CCR model) because the total internal weight in each category of each level of hierarchy must be equal to one. This will result in the efficiency score of each DMU calculated from this network model will not exceed that calculated from the one level model. Hence, it will increase the discriminating power of DEA to a certain extent. Furthermore, the hierarchical structure described has different functions or activities in the model and the weights on one level can be treated differently from the other levels (Shen et al., 2011). 


\section{HIERARCHICAL STRUCTURE OF A UNIVERSITY FACULTY}

The administration of a university faculty is usually structured in a hierarchical form since the university faculty has three major functions (teaching, research and services) that utilizes the resources to produce multiple outputs. The outputs are related to different functions. Kao (2015) applies the hierarchical network DEA model to measure efficiency of a university where only teaching has subordinate components which are undergraduate and graduate. This paper extends Kao's work where teaching and other services are further divided into several subordinate components at the next level in the hierarchical structure. Teaching is further divided into tasks at the undergraduate level, master level and $\mathrm{PhD}$ level, while other services are divided into consultation and active activities resulted as the MoU (Memorandum of Understanding) / MoA (Memorandum of Agreement) /LoI (Letter of Intent) with institutions or agencies at international or national levels. Every component consumes all the major inputs distributed to it in order to produce a number of outputs. From the above situation, the hierarchical structure can be formed as in Figure 1. In this paper, DMUs are faculties at a university in Malaysia. Factors that influence the efficiency of the university faculty are identified to be the inputs or the outputs. In general, inputs and outputs to be selected must be relevant and directly aligned with the goals and objectives of the university's faculty (Al-Turki \& Duffuaa, 2003; Alwadood et al., 2011). Teaching and research have been regarded as two of the main tasks of the university in most studies on the performance of universities (Johnes \& Yu, 2008; Kao \& Hung, 2008; Kao, 2012; Monfared \& Safi, 2013; Chuanyi et al., 2016). However, it is difficult to measure the performance of these two major tasks (Kao \& Hung, 2008). Hence, we need to obtain specific indicators that can represent both achievements of these tasks. We must also take into account the resources that have been used by the faculty in carrying out these dutie.

From the previous literature (Johnes, 2006; Kao \& Hung, 2008; Monfared \& Safi, 2013), the main input of a faculty system should include foreign and local academicians of different ranks and administrative staff. Subsequently, the output variables should measure the aim of the university to produce the quality output for all major functions of a university which include the number of graduates, the number of publications, the number of main researchers based on different types of grants, the number of expert lecturers, amount of grants in monetary value, and the number of collaboration activities. It should be noted that the number of collaboration activities is suggested as a new output variable of the system in this study. The activities or programs under the MoU/MoA/LoI are parts of the strategic plan of a university to enhance and strengthen the network of cooperative relationships with other national 
and international institutions. The examples of collaboration or cooperation activity are exchange of students and staff, seminars, research programs, joint academic cooperation and industrial training for students and staff. These new subordinate components and outputs are considered in this study due to current education circumstances in Malaysia. The summary of the inputs and outputs selected for efficiency measurement is shown in Table 1.

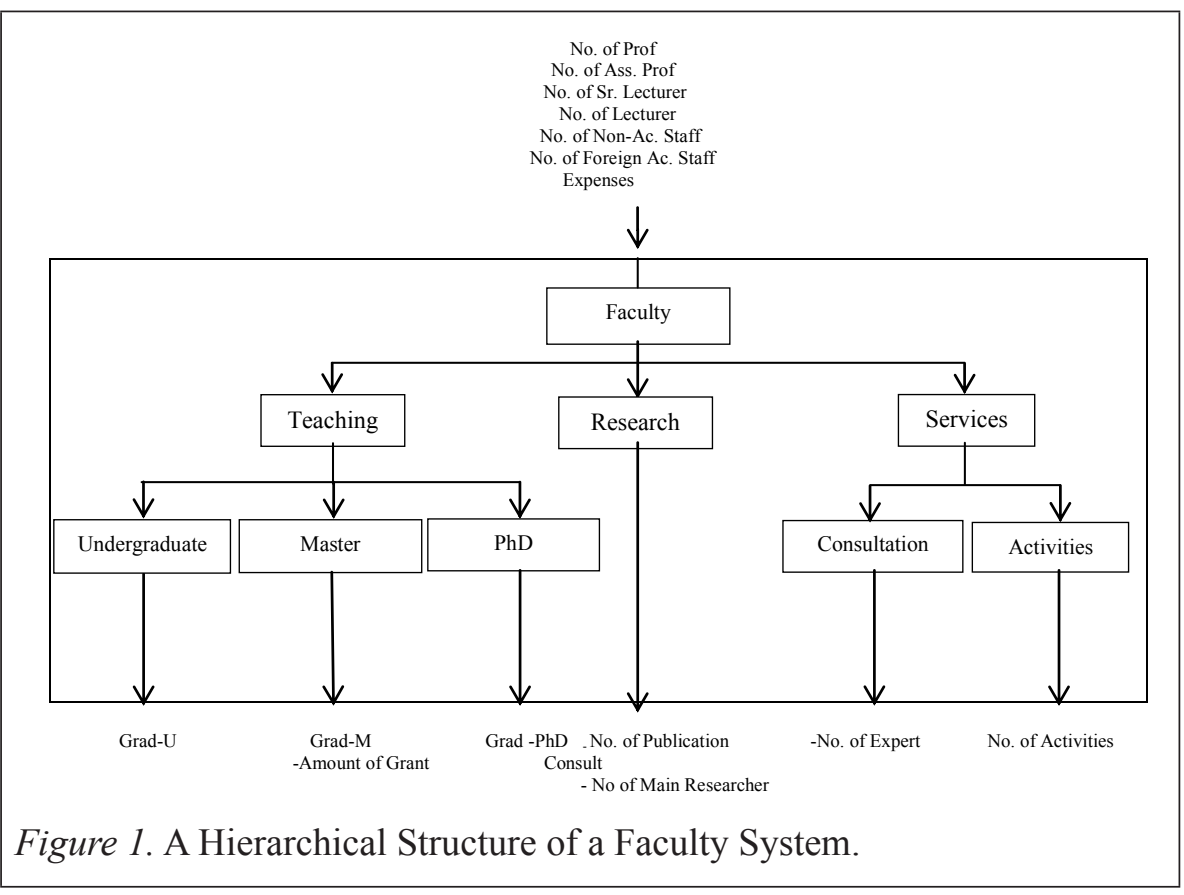

Table 1

Input and Output Variables for Efficiency Measurement

\section{Input}

1. Number of Professors

2. Number of Associate Professors

3. Number of Senior Lecturers

4. Number of lecturers

5. Number of foreign academic staff

6. Number of non-academic staff

7. Expenses

\section{Output}

1. Number of graduates from undergraduate program

2. Number of graduates from master program

3. Number of graduates from $\mathrm{PhD}$ program

4. Number of publications

5. Amount of grants (RM)

6. Number of main researchers based on different types of grants

7. Number of expert lecturers

8. Number of collaboration activities done under MoU/LoI (new variable) 
Figure 2 portrays the hierarchical structure where the inputs and outputs are as in Figure 1, but with their mathematical symbols to be used in the mathematical model later, where the $y$ 's represent the outputs, whereas the $x$ 's are the inputs. The $\delta$ 's are the weights of main inputs, while $\alpha$ 's are the weights of the inputs of the subordinate's components. The L0, L1 and L2 represent the levels of the hierarchical structure in Figure 2. As in the traditional DEA application, every DMU in the network DEA model to be assessed must also have the same structure (Kao, 2015). Every component of each DMU at the first stage is assumed to distribute the inputs to its subordinate components in the second stage. If a component does not have a subordinate component, then it utilizes all the inputs distributed to it alone to produce several outputs.

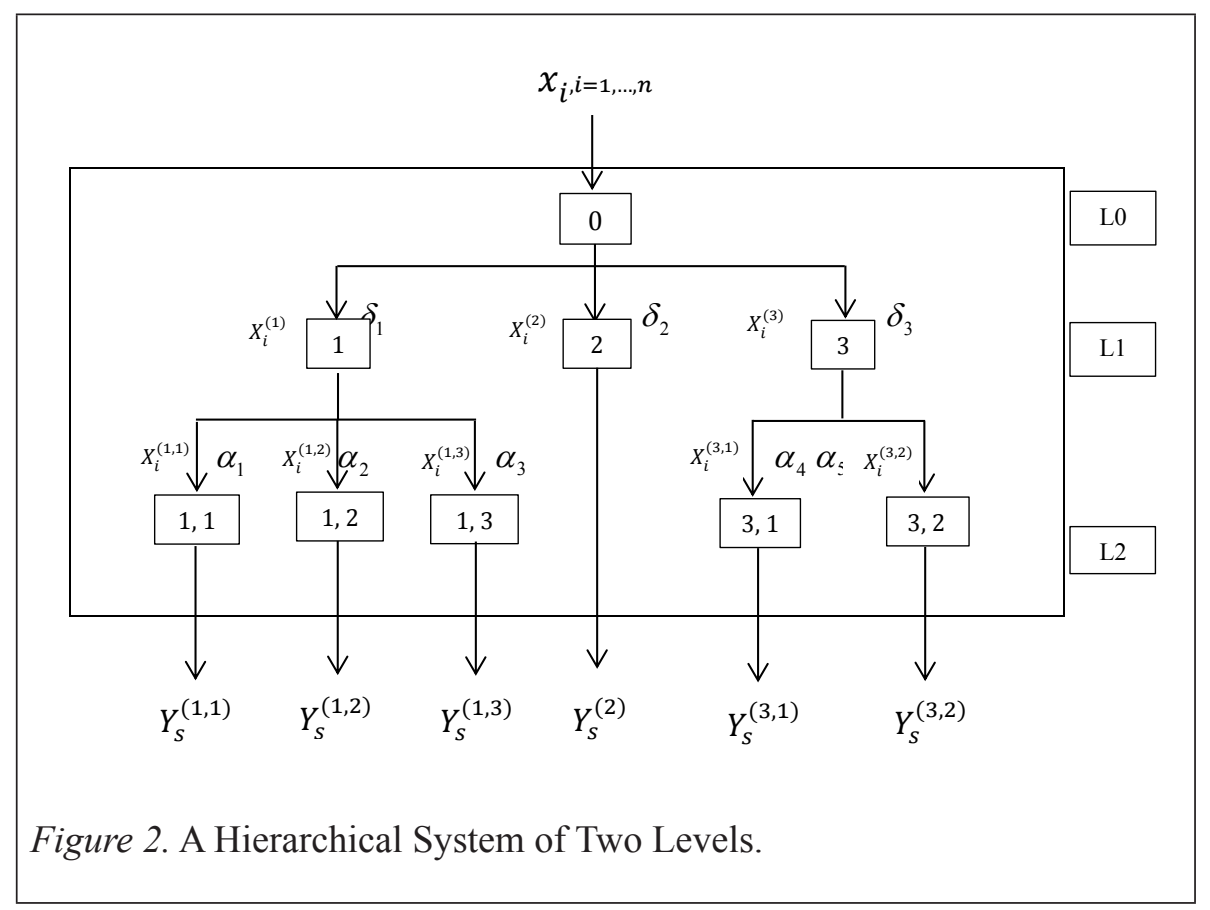

\section{THE PROPOSED MODEL}

The hierarchical structure as in Figure 2, is the proposed network DEA model that becomes the basis to estimate the efficiency of 14 faculties at a public university in Malaysia for year 2015, with six (6) inputs and eight (8) outputs. In the hierarchical process, the inputs in each faculty are shared among different components. For example, a professor has responsibilities in teaching, doing research, and giving service to community. Therefore, it 
is difficult for them to describe the amount of effort they have allocated to achieving each of these goals (Kao, 2015). For that reason, the weights of the function should be determined. For this study, we calculated weights based on Key Performance Indicator (KPI) of the university faculty itself, by assuming that every university faculty allocates approximately $44 \%, 39 \%$ and $17 \%$ of each input to teaching, research and other services respectively. Let $\delta_{1}, \delta_{2}$ and $\delta_{3}$ be the proportion of weights of each input allocated to these functions respectively. Hence, the relations between these inputs are $\delta_{1} \cong 1.128 \delta_{2}, \delta_{2}$ $\cong 2.294 \delta_{3}, \delta_{1} \cong 2.588 \delta_{3}, \delta_{1}+\delta_{2}+\delta_{3}=1$.

Since this relation is just an approximation, the proportions are expressed in ranges as: $0.5 \delta_{2} \leq \delta_{1} \leq 2 \delta_{2}, \delta_{3} \leq \delta_{1} \leq 4 \delta_{3}, \delta_{3} \leq \delta_{2} \leq 4 \delta_{3}$ (Kao, 2015). Furthermore, there are three tasks of teaching: undergraduate, master and $\mathrm{PhD}$, every faculty is assumed to allocate approximately $50 \%\left(\alpha_{1}\right), 30 \%\left(\alpha_{2}\right)$ and $20 \%\left(\alpha_{3}\right)$ of each input to undergraduate, master and $\mathrm{PhD}$ respectively. The corresponding relations are $\alpha_{1} \cong 1.667 \alpha_{2}, \alpha_{2} \cong 1.5 \alpha_{3}, \alpha_{1} \cong 2.5 \alpha_{3}, \alpha_{1}+\alpha_{2}+\alpha_{3}=1$. The proportions can be expressed as follows: $0.5 \alpha_{2} \leq \alpha_{1} \leq 2 \alpha_{2}, \alpha_{3} \leq \alpha_{1} \leq 4 \alpha_{3}$, $0.5 \alpha_{3} \leq \alpha_{2} \leq 2 \alpha_{3}$

Lastly, there are two categories of services, consultation and collaboration activities. We assume that each university faculty allocates similar amounts of inputs to both categories; that is, $\alpha_{4} \cong \alpha_{5}, \alpha_{4}+\alpha_{5}=1$, and the relation is represented by $0.5 \alpha_{5} \leq \alpha_{4} \leq 2 \alpha_{5}$.

Consider a system with the basic hierarchical structure, we assume that each of the $T$ th component of DMU $j(j=1,2, \ldots \ldots, m) x_{i j}^{(T)}$, has inputs $i(\mathrm{i}=1$, $2, \ldots, n)$ and $y_{s j}^{(T)}$, output $s(s=1,2, \ldots, r)$. Let $V_{i}$ be the input weights and $U_{s}$ be the output weights. In general, the conventional black-box DEA model for measuring the efficiency of DMU $j$, under Constant Returns to Scale (CCR) (Kao, 2015) can be formulated as follows:

$$
E_{d}^{C C R}=\max \frac{\sum_{s=1}^{r} U_{s}\left(Y_{s d}^{(1,1)}+Y_{s d}^{(1,2)}+Y_{s d}^{(1,3)}+Y_{s d}^{(2)}+Y_{s d}^{(3,1)}+Y_{s d}^{(3,2)}\right)}{\sum_{i=1}^{n} V_{i} X_{i d}}
$$

subject to

$$
\begin{aligned}
& \sum_{s=1}^{r} U_{S}\left(Y_{s j}^{(1,1)}+Y_{s j}^{(1,2)}+Y_{s j}^{(1,3)}+Y_{s j}^{(2)}+Y_{s j}^{(3,1)}+Y_{s j}^{(3,2)}\right)-\sum_{i-1}^{n} V_{i} X_{i j} \leq 0, j=1, \ldots, m \\
& U_{S}, V_{i} \geq 0, s=1, \ldots, r, i=1, \ldots, n
\end{aligned}
$$

Thus, based upon the basic hierarchical model, we can establish the following model for Figure 2: 


$$
\mathrm{E}_{d}^{H N W}=\max \sum_{s=1}^{r} U_{s}\left(Y_{s d}^{(1,1)}+Y_{s d}^{(1,2)}+Y_{s d}^{(1,3)}+Y_{s d}^{(2)}+Y_{s d}^{(3,1)}+Y_{s d}^{(3,2)}\right)
$$

subject to:

$$
\begin{aligned}
& \sum_{i=1}^{n} V_{i} X_{i j}=1 \\
& \sum_{s=1}^{r} U_{s} Y_{s j}^{(1,1)}-\sum_{i=1}^{n} V_{i} \delta_{1} \alpha_{1} X_{i j}^{(1,1)} \leq 0, j=1, \ldots \ldots m \\
& \sum_{s=1}^{r} U_{S} Y_{s j}^{(1,2)}-\sum_{i=1}^{n} V_{i} \delta_{1} \alpha_{2} X_{i j}^{(1,2)} \leq 0, j=1, \ldots . m \\
& \sum_{s=1}^{r} U_{s} Y_{s j}^{(1,3)}-\sum_{i=1}^{n} V_{i} \delta_{1} \alpha_{3} X_{i j}^{(1,3)} \leq 0, j=1, \ldots \ldots m \\
& \sum_{s=1}^{r} U_{s} Y_{s j}^{(2)}-\sum_{i=1}^{n} V_{i} \delta_{2} X_{i j}^{(2)} \leq 0, j=1, \ldots . m \\
& \sum_{s=1}^{r} U_{S} Y_{s j}^{(3,1)}-\sum_{i=1}^{n} V_{i} \delta_{3} \alpha_{4} X_{i j}^{(3,1)} \leq 0, j=1, \ldots . . m \\
& \sum_{S=1}^{r} U_{S} Y_{s j}^{(3,2)}-\sum_{i=1}^{n} V_{i} \delta_{3} \alpha_{5} X_{i j}^{(3,2)} \leq 0, j=1, \ldots . . m \\
& 0.5 \delta_{2} \leq \delta_{1} \leq 2 \delta_{2}, \delta_{3} \leq \delta_{1} \leq 4 \delta_{3}, \delta_{3} \leq \delta_{2} \leq 4 \delta_{3}, \delta_{1}+\delta_{2}+\delta_{3}=1 \\
& 0.5 \alpha_{2} \leq \alpha_{1} \leq 2 \alpha_{2}, \alpha_{3} \leq \alpha_{1} \leq 4 \alpha_{3}, 0.5 \alpha_{3} \leq \alpha_{2} \leq 2 \alpha_{3}, \alpha_{1}+\alpha_{2}+\alpha_{3}=1 \\
& 0.5 \alpha_{5} \leq \alpha_{4} \leq 2 \alpha_{5}, \alpha_{4}+\alpha_{5}=1, U_{s}, V_{i} \geq 0, s=1, \ldots, r, i=1, \ldots, n
\end{aligned}
$$

After the optimal solution $\left(U^{*}, V^{*}\right)$ is obtained, the efficiencies of every component and subordinator are calculated as:

$$
\begin{aligned}
& E_{d}^{(U T)}=\sum_{S=1}^{r} U_{S}^{*} Y_{s d}^{(1,1)} / \sum_{i=1}^{n} V_{i}^{*} \delta_{1} \alpha_{1} X_{i d}^{(1,1)} \\
& E_{d}^{(M T)}=\sum_{s=1}^{r} U_{s}^{*} Y_{S d}^{(1,2)}, \sum_{i=1}^{n} V_{i}^{*} \delta_{1} \alpha_{2} X_{i d}^{(1,2)} \\
& E_{d}^{(P H D)}=\sum_{S=1}^{r} U_{S}^{*} Y_{S d}^{(1,3)}, \sum_{i=1}^{n} V_{i}^{*} \delta_{1} \alpha_{3} X_{i d}^{(1,3)} \\
& E_{d}^{(\operatorname{Re} s e a r c h)}=\sum_{S=1}^{r} U_{S}^{*} Y_{S d}^{(2)}, \sum_{i=1}^{n} V_{i}^{*} \delta_{2} X_{i d}^{(2)} \\
& E_{d}^{(\text {Cons })}=\sum_{s=1}^{r} U_{s}{ }^{*} Y_{s d}^{(3,1)}, \sum_{i=1}^{n} V_{i}^{*} \delta_{3} \alpha_{4} X_{i d}^{(3,1)} \\
& E_{d}^{(\text {Activities })}=\sum_{s=1}^{r} U_{S}^{*} Y_{s d}^{(3,2)}, \sum_{i=1}^{n} V_{i}^{*} \delta_{3} \alpha_{5} X_{i d}^{(3,2)}
\end{aligned}
$$




$$
\begin{aligned}
& E_{d}^{(\text {Teaching })}=\sum_{S=1}^{r} U_{S}{ }^{*}\left(Y_{S d}^{(1,1)}+Y_{s d}^{(1,2)}+Y_{S d}^{(1,3)}\right) / \sum_{i=1}^{n} V_{i}^{*} \delta_{1} X_{i d} \\
& E_{d}^{(\text {Services })}=\sum_{S=1}^{r} U_{S}{ }^{*}\left(Y_{S d}^{(3,1)}+Y_{S d}^{(3,2)}\right) / \sum_{i=1}^{n} V_{i}{ }^{*} \delta_{3} X_{i d}
\end{aligned}
$$

The model is run several times in identifying the relative efficiency scores of every DMU and every component in the hierarchical system. If DMUs and components in the hierarchical system achieved $100 \%$ efficiency rating, then the DMUs are considered efficient or vice versa.

Theorem 1 (Tone \& Tsutsui, 2009). A DMU is fully efficient if and only if all components are also efficient. Hence, as a result it may happen that none of the DMUs is efficient which is contradictory to the results from the conventional DEA model.

\section{Nomenclature}

$X_{i j}^{(T)} \quad=$ The $i$ th input of the $T$ th unit of DMU $j$

$Y_{s j}^{(T)} \quad=$ The $s$ th output of the Tth unit of DMU $j$

$\delta_{k}=$ The proportions of each inputs allocated amounts of resources to teaching, research and services

$\alpha_{k} \quad=$ The proportions of each inputs allocated amounts of resources to undergraduate, master, $\mathrm{PhD}$, consultation and activities

$L_{0} \quad=$ The top level of the hierarchical

$L_{2} \quad=$ The second level of the hierarchical

Us $\quad=$ The output weights

$V i \quad=$ The input weights

\section{APPLICATION}

Eq. (1) to Eq. (3) represent model (1) and Eq. (4) to Eq. (14) represent model (2). Model (1) and (2) were applied to measure the relative efficiency of 14 faculties at a university in Malaysia. Model (1) is a conventional black-box CCR model where the internal structure of the hierarchical system is ignored, while model (2) is the proposed network DEA model for systems with hierarchical structures that reflects the internal structure of the hierarchical system. The black-box model is selected as a comparative method to the proposed method since they are comparable, due to the fact that both methods belong to the same family with the same underpinning theory but with different structures. The results obtained by both models are summarized in Table 2. From Table 
2, the efficiency scores $\left(\mathrm{E}_{\mathrm{BB}}\right)$ using model (1) are shown in the first column, in which there are 12 efficient faculties, namely, DMU 1, DMU 2, DMU 3, DMU 4, DMU 5, DMU 7, DMU 8, DMU 9, DMU 11, DMU 12, DMU 13 and DMU 14, and only two are inefficient, namely, DMU 6 and DMU 10. The scores obtained by the black box model tend to be higher than those of the network model. Basically, these two models are unfair to be compared since the number of inputs is different between the two models (Tone \& Tsutsui, 2009). However, these results clearly demonstrate that the discriminate power of the black box model is lower than of the network model. In addition, these results are not very informative because the results do not discriminate the order of the efficient faculties as well as not able to disentangle the efficiency of faculty into those of its functions. In an effort to acquire this information, the proposed network DEA model (2) is used and its results, $\mathrm{E}_{\mathrm{NW}}$, show that none of the faculties is efficient as a whole because there is always a function or component in the hierarchical system for each faculty which is inefficient as shown in the second column of Table 2.

In the proposed network DEA model, faculties are considered to be fully efficient when every function is efficient. When we compare both models, the result of model (2) is more informative as it provides efficiency score for each function of the faculty, and the ranking of the efficient faculties is provided. Hereby, the management of the university faculties is able to identify the cause of inefficiencies for every function.

Based on the results obtained by the proposed network DEA model, all faculties are considered as inefficient as all of them have score of less than 1.0. However, the highest score is Faculty 9 (0.9068), since it has managed to gain a perfect score of 1.0 for undergraduate teaching, $\mathrm{PhD}$ and research. The same pattern of results are shown for Faculty 7 but with different overall results with $\mathrm{E}_{\text {Network }}=0.8884$, and Faculty 11 with $\mathrm{E}_{\mathrm{NW}}=0.8586$. While, Faculty 13 has the lowest overall inefficient score which is 0.6266 and also is not efficient at all functions in the structure of the hierarchical system with $\mathrm{E}_{\text {UnderGraduate }}=0.7525$; $\mathrm{E}_{\text {Master }}=0.1723 ; \mathrm{E}_{\mathrm{PHD}}=0.4331 ; \mathrm{E}_{\text {Research }}=0.6947 ; \mathrm{E}_{\text {consultations }}=0.0784 ; \mathrm{E}_{\text {Activities }}=$ $0.9813 ; \mathrm{E}_{\text {Services }}=0.6803$; and $\mathrm{E}_{\text {Teaching }}=0.5411$. The results also indicate that nine faculties are efficient in research (Faculty 1, Faculty 2, Faculty 3, Faculty 4, Faculty 5, Faculty 7, Faculty 9, Faculty 11 and Faculty 12). None of the 14 faculties are efficient in service and teaching. As a whole, the efficiency scores resulted from the black box model tend to be higher than the network model. This shows that the discrimination power of network model is higher than the black box model (Tone \& Tsutsui, 2009, Shen et al., 2011). This hierarchical model is less flexible than the normal Charnes-Cooper-Rhodes (CCR) model (Charnes et al., 1978) as the total internal weights in each components of each level must be equal to one. In general, the efficiency score of the hierarchical 
model for each DMU will not exceed the scores that are calculated at the level one of the model. Thus, this will improve the discrimination power of DEA to a certain extent (Shen et al., 2011).

In summary, the results from the proposed model as portrayed in Table 2 can help the dean or the management of a faculty to identify the functions in which they need to improve to be efficient as a whole. For example, Faculty 10 is not efficient mainly due to its inefficiency in consultation, and for Faculty 12 is due to inefficiencies in master teaching, consultation and services. Therefore, if these two faculties want to achieve efficiency, it will require them to focus on improving the inefficient functions or components.

Table 2

Efficiency Scores for the 14 University Faculties

\begin{tabular}{|c|c|c|c|c|c|c|c|c|c|c|}
\hline DMU & $\mathbf{E}_{\mathrm{BB}}$ & $\mathbf{E}_{\mathrm{NW}}$ & $\mathbf{E}_{\mathrm{UG}}$ & $\mathbf{E}_{\mathrm{M}}$ & $\mathbf{E}_{\text {PHD }}$ & $\mathbf{E}_{\mathrm{RES}}$ & $\mathbf{E}_{\mathrm{CONS}}$ & $\mathbf{E}_{\mathrm{ACT}}$ & $\mathbf{E}_{\mathrm{s}}$ & $\mathbf{E}_{\mathrm{T}}$ \\
\hline 1 & [1] & $\begin{array}{c}0.8676 \\
{[5]}\end{array}$ & $\begin{array}{c}0.7748 \\
{[7]}\end{array}$ & $\begin{array}{c}1.0000 \\
{[1]}\end{array}$ & $\begin{array}{c}0.6523 \\
{[7]}\end{array}$ & $\begin{array}{c}1.0000 \\
{[1]}\end{array}$ & $\begin{array}{c}0.0670 \\
{[11]}\end{array}$ & $\begin{array}{c}0.3807 \\
{[9]}\end{array}$ & $\begin{array}{c}0.2761 \\
{[10]}\end{array}$ & $\begin{array}{c}0.8568 \\
{[4]}\end{array}$ \\
\hline 2 & [1] & $\begin{array}{c}0.8950 \\
{[3]}\end{array}$ & $\begin{array}{c}0.9923 \\
{[5]}\end{array}$ & $\begin{array}{c}0.2264 \\
{[7]}\end{array}$ & $\begin{array}{c}0.8259 \\
{[5]}\end{array}$ & $\begin{array}{c}1.0000 \\
{[1]}\end{array}$ & $\begin{array}{c}0.3325 \\
{[4]}\end{array}$ & $\begin{array}{c}1.0000 \\
{[1]}\end{array}$ & $\begin{array}{c}0.7775 \\
{[3]}\end{array}$ & $\begin{array}{c}0.7701 \\
{[5]}\end{array}$ \\
\hline 3 & & $\begin{array}{c}0.7722 \\
{[9]}\end{array}$ & $\begin{array}{c}0.2561 \\
{[14]}\end{array}$ & $\begin{array}{c}0.3299 \\
{[6]}\end{array}$ & $\begin{array}{c}0.7579 \\
{[6]}\end{array}$ & $\begin{array}{c}1.0000 \\
{[1]}\end{array}$ & $\begin{array}{c}0.1227 \\
{[8]}\end{array}$ & $\begin{array}{c}0.5648 \\
{[6]}\end{array}$ & $\begin{array}{c}0.4174 \\
{[6]}\end{array}$ & $\begin{array}{c}0.4716 \\
{[11]}\end{array}$ \\
\hline 4 & & $\begin{array}{c}0.7901 \\
{[7]}\end{array}$ & $\begin{array}{c}0.5849 \\
{[11]}\end{array}$ & $\begin{array}{r}0.09 \\
{[11}\end{array}$ & $\begin{array}{c}0.3460 \\
{[14]}\end{array}$ & $\begin{array}{c}1.0000 \\
{[1]}\end{array}$ & $\begin{array}{c}0.1752 \\
{[7]}\end{array}$ & $\begin{array}{c}1.0000 \\
{[1]}\end{array}$ & $\begin{array}{c}0.7251 \\
{[4]}\end{array}$ & $\begin{array}{c}0.4108 \\
{[13]}\end{array}$ \\
\hline 5 & $\begin{array}{c}1.0000 \\
{[1]}\end{array}$ & $\begin{array}{c}0.8973 \\
{[2]}\end{array}$ & $\begin{array}{c}0.5937 \\
{[10]}\end{array}$ & $\begin{array}{c}0.6976 \\
{[3]}\end{array}$ & $\begin{array}{c}0.8672 \\
{[4]}\end{array}$ & $\begin{array}{c}1.0000 \\
{[1]}\end{array}$ & $\begin{array}{c}0.3885 \\
{[2]}\end{array}$ & $\begin{array}{c}1.0000 \\
{[1]}\end{array}$ & $\begin{array}{c}0.7962 \\
{[2]}\end{array}$ & $\begin{array}{c}0.7057 \\
{[6]}\end{array}$ \\
\hline 6 & & $\begin{array}{c}0.6567 \\
{[13]}\end{array}$ & $\begin{array}{c}0.5521 \\
{[12]}\end{array}$ & & & & & & & $\begin{array}{c}0.4474 \\
{[12]}\end{array}$ \\
\hline 7 & & $\begin{array}{r}0.88 \\
{[4}\end{array}$ & $\begin{array}{r}1.00 \\
{[1}\end{array}$ & $\begin{array}{r}0.59 \\
{[4}\end{array}$ & $\begin{array}{r}1.00 \\
{[1}\end{array}$ & $\begin{array}{r}1.00 \\
{[1}\end{array}$ & & $\begin{array}{c}0.5594 \\
{[7]}\end{array}$ & & $\begin{array}{c}0.9185 \\
{[2]}\end{array}$ \\
\hline 8 & & $\begin{array}{c}0.7819 \\
{[8]}\end{array}$ & $\begin{array}{c}0.7684 \\
{[8]}\end{array}$ & & $\begin{array}{c}0.5938 \\
{[9]}\end{array}$ & & $\begin{array}{c}1.0000 \\
{[1]}\end{array}$ & $\begin{array}{c}0.6348 \\
{[5]}\end{array}$ & $\begin{array}{c}0.8783 \\
{[1]}\end{array}$ & $\begin{array}{c}0.5565 \\
{[9]}\end{array}$ \\
\hline 9 & $\begin{array}{c}1.0000 \\
{[1]}\end{array}$ & $\begin{array}{c}0.9068 \\
{[1]}\end{array}$ & $\begin{array}{c}1.0000 \\
{[1]}\end{array}$ & $\begin{array}{c}0.8153 \\
{[2]}\end{array}$ & $\begin{array}{c}1.0000 \\
{[1]}\end{array}$ & $\begin{array}{c}1.0000 \\
{[1]}\end{array}$ & $\begin{array}{c}0.2388 \\
{[5]}\end{array}$ & $\begin{array}{c}0.4000 \\
{[8]}\end{array}$ & $\begin{array}{c}0.3463 \\
{[8]}\end{array}$ & $\begin{array}{c}0.9631 \\
{[1]}\end{array}$ \\
\hline 10 & & $\begin{array}{c}0.6578 \\
{[12]}\end{array}$ & $\begin{array}{c}0.7936 \\
{[6]}\end{array}$ & $\begin{array}{c}0.2279 \\
{[8]}\end{array}$ & $\begin{array}{c}0.6382 \\
{[8]}\end{array}$ & $\begin{array}{c}0.7944 \\
{[13]}\end{array}$ & $\begin{array}{c}0.0416 \\
{[14]}\end{array}$ & $\begin{array}{c}0.3162 \\
{[10]}\end{array}$ & $\begin{array}{c}0.2247 \\
{[11]}\end{array}$ & $\begin{array}{c}0.6158 \\
{[8]}\end{array}$ \\
\hline 11 & $\begin{array}{c}1.0000 \\
{[1]}\end{array}$ & $\begin{array}{c}0.8586 \\
{[6]}\end{array}$ & $\begin{array}{c}1.0000 \\
{[1]}\end{array}$ & $\begin{array}{c}0.5805 \\
{[5]}\end{array}$ & $\begin{array}{c}1.0000 \\
{[1]}\end{array}$ & $\begin{array}{c}1.0000 \\
{[1]}\end{array}$ & $\begin{array}{c}0.1343 \\
{[6]}\end{array}$ & $\begin{array}{c}0.1538 \\
{[13]}\end{array}$ & $\begin{array}{c}0.1473 \\
{[12]}\end{array}$ & $\begin{array}{c}0.9161 \\
{[3]}\end{array}$ \\
\hline 12 & $\begin{array}{c}1.0000 \\
{[1]}\end{array}$ & $\begin{array}{c}0.6704 \\
{[11]}\end{array}$ & $\begin{array}{c}0.3150 \\
{[13]}\end{array}$ & $\begin{array}{c}0.0695 \\
{[12]}\end{array}$ & $\begin{array}{c}0.4968 \\
{[11]}\end{array}$ & $\begin{array}{c}1.0000 \\
{[1]}\end{array}$ & $\begin{array}{c}0.0448 \\
{[12]}\end{array}$ & $\begin{array}{c}0.1192 \\
{[14]}\end{array}$ & $\begin{array}{c}0.0944 \\
{[14]}\end{array}$ & $\begin{array}{c}0.3386 \\
{[14]}\end{array}$ \\
\hline 13 & $\begin{array}{c}1.0000 \\
{[1]}\end{array}$ & $\begin{array}{c}0.6266 \\
{[14]}\end{array}$ & $\begin{array}{c}0.7525 \\
{[9]}\end{array}$ & 0.1723 & $\begin{array}{c}0.4331 \\
{[2]}\end{array}$ & $\begin{array}{c}0.6947 \\
{[14]}\end{array}$ & $\begin{array}{c}0.0784 \\
{[10]}\end{array}$ & $\begin{array}{c}0.9813 \\
{[4]}\end{array}$ & $\begin{array}{c}0.6803 \\
{[5]}\end{array}$ & $\begin{array}{c}0.5411 \\
{[10]}\end{array}$ \\
\hline 14 & $\begin{array}{c}1.0000 \\
{[1]}\end{array}$ & $\begin{array}{c}0.7009 \\
{[10]}\end{array}$ & $\begin{array}{c}1.0000 \\
{[1]}\end{array}$ & $\begin{array}{c}0.0612 \\
{[14]}\end{array}$ & $\begin{array}{c}0.3843 \\
{[13]} \\
\end{array}$ & $\begin{array}{c}0.8875 \\
{[10]} \\
\end{array}$ & $\begin{array}{c}0.0448 \\
{[13]}\end{array}$ & $\begin{array}{c}0.1779 \\
{[12]} \\
\end{array}$ & $\begin{array}{c}0.1336 \\
{[13]} \\
\end{array}$ & $\begin{array}{c}0.6438 \\
{[7]} \\
\end{array}$ \\
\hline
\end{tabular}

$B B=$ Black Box, $N W=$ Network, $U G=$ Undergraduate, $M=$ Master, $P H D=P h D, R E S=$ Research, $C O N S=$ Consultation, $A C T=$ Activities under MoU/LoI, $S=$ Services, $T=$ Teaching 


\section{CONCLUSIONS}

This paper proposed a model to measure relative efficiency of a university faculty by using a hierarchical network DEA model. This would contribute an alternative methodology in efficiency evaluation of a university since in reality, universities have a hierarchical structure with components at different stages. The black-box DEA model ignores the internal structure of hierarchical system in measuring efficiency. Due to that, the results obtained by the traditional black box model cannot identify inefficient factors of DMUs and consequently the results may give a misleading picture. Thus, this paper has developed a hierarchical network DEA model in order to demonstrate a strong discriminant power in evaluations of universities especially in identifying efficient and inefficient factors. In a future study, the proposed network DEA model will be extended further by considering more new cases to components or subordinate components in the hierarchical system. Besides that, there may existed some intermediate components do produce outputs itself although its having subordinate components. Nevertheless, this paper has contributed new insights to the performance evaluation particularly in measuring the efficiency of a university faculty.

\section{ACKNOWLEDGMENT}

The research is funded by Universiti Utara Malaysia and the Malaysian Ministry of Higher Education under the Fundamental Research Grant Scheme (FRGS) with S/O Code 12179, 2011-2017.

\section{REFERENCES}

Abdullah, F., Ku-Mahamud, K. R, Ahmad, F., Ghani N.F.A., \& Kasim, M. M. (2012). Relative efficiency of projects using data envelopment analysis: A case study. International Journal of Digital Content Technology and its Applications, 6(9), 310-318.

Ahmi, A. \& Mohamad, R. (2016). Evaluating accessibility of Malaysian public universities websites using AChecker and WAVE. Journal of Information and Communication Technology, 15(2), 193-214.

Aigner, D., Lovell, C. A. K., \& Schmidt, P. (1977). Formulation and estimation of stochastic frontier production function models. Journal of Econometrics, 6(1), 21-37. 
Bates, J. (1997). Measuring predetermined socioeconomic inputs when assessing the efficiency of educational outputs, Applied Economics, 29, 85-93.

Al-Turki, U., \& Duffuaa, S. (2003). Performance measures for academic departments. The International Journal of Educational Management, 17, 330-338.

Alwadood, Z., Mohd Noor, N., \& Kamarudin, M. F. (2011). Performance measure of academic departments using data envelopment analysis. In ISBEIA Symposium on Business, Engineering and Industrial Applications, (pp. 395-399). Langkawi.

Avilés, S., Güemes, D., Cook, W.D., \& Cantú, H. (2015). Time-staged outputs in DEA. Omega International Journal of Management Science, 55, 1-9.

Chakraborty, K., Biswas, B. \& Lewis, W. C. (2001). Measurement of technical efficiency in public education: a stochastic and non-stochastic production function approach, Southern Economic Journal, 67, 889905.

Castelli L, Pesenti R, \& Ukovich W. (2004). DEA-like models for the efficiency evaluation of hierarchically structured units. European Journal of Operational Research, 154, 465-76.

Charnes, A., Cooper, W. W., \& Rhodes, E. (1978). Measuring the efficiency of decision-making units. European Journal of Operational Research, 2, 429-444.

Chuanyi, W., Xiaohong, L., \& Shikui, Z. (2016). The relative efficiencies of research universities of science and technology in China: Based on the data envelopment analysis and stochastic frontier analysis. Eurasia Journal of Mathematics, Science \& Technology Education, 12 (10), 2753-2770.

Coelli, T. J., Rao, D. S. P., O'Donnell, C. J., \& Battese, G. E. (2005). An introduction to efficiency and productivity analysis. USA: Springer Science \& Business Media.

Collier, T., Johnson, A. L., \& Ruggiero, J. (2011). Technical efficiency estimation with multiple inputs and multiple outputs using regression analysis. European Journal of Operational Research, 208, 153- 160.

Cook, W. D., \& Seiford, L. M. (2009). Data envelopment analysis (DEA) Thirty years on. European Journal of Operational Research, 192(1), $1-17$.

Cordero-Ferrera J.M, Pedraja-Chaparro, F., \& Salinas-Jiménez, J. (2008). Measuring efficiency in education: an analysis of different approaches for incorporating non-discretionary inputs, Applied Economics, 40(10), 1323-1339. 
Dan, M. C. (2013). Why should university and business cooperate? Discussion of advantages and disadvantages. International Journal of Economic Practices and Theories, 3, 67-74.

Färe R, \& Grosskopf S. (2000). Network DEA. Socio-Economic Planning Sciences, 34, 35-49.

Grosskopf, S., Hayes, K.J., \& Taylor, L.L (2014). Applied efficiency analysis in education. Economic Business Letters, 3, 19-26.

Gua, C., Shureshjani, R. A., Foroughi, A. A., \& Zhu, J. (2017). Decomposition weights and overall efficiency in two-stage additive network DEA. European Journal of Operational Research, 257 (3), 896 - 906.

Huguenin, J.M. (2015). Determinants of school efficiency: The case of primary schools in the State of Geneva, Switzerland. International Journal of Education Management, 29, 539-562.

Izadi, H., Johnes, G., Oskrochi, R., \& Crouchley, R. (2002). Stochastic frontier estimation of a CES cost function: The case of higher education in Britain. Economics of Education Review, 21, 63-71.

Ismail, I., Ramalingam, S., Azahan, A. H., \& Khezrimotlagh, D. (2014). Relative efficiency of public universities in Malaysia. Scholars Journal of Economics Business and Management, 1(11), 606-612.

Johnes, J. (1996). Performance assessment in higher education in Britain. European Journal of Operational Research, 89, 18-33.

Johnes, J. (2006). Data envelopment analysis and its application to the measurement of efficiency in higher education. Economics of Education Review, 25, 273-288.

Johnes, J., \& Yu, L. (2008). Measuring the research performance of Chinese higher education institutions using data envelopment analysis. China Economic Review, 19, 679-696.

Johnes, J. (2015). Operational research in education. European Journal of Operational Research, 243(3), 683-696.

Kao, \& Hung, HT. (2008). Efficiency analysis of university departments: An empirical study. The International Journal of Management Science, 36, 653-664.

Kao, C. (2012). Efficiency decomposition for parallel production systems. Journal of the Operational Research Society, 63, 64-71.

Kao, C. (2015). Efficiency measurement for hierarchical network systems. The International Journal of Management Science, 51, 121-127.

Kao, C. (2017). Efficiency measurement and frontier projection identification for general two-stage systems in data envelopment analysis. European Journal of Operational Research, 261 (2), 679-689. 
Kasim, M. M., Kashim, R., \& Khan, S. A. N. (2017). A linear programmingbased model to measure efficiency and effectiveness of undergraduate programs. Journal of Information and Communication Technology, 16 (2), 394-407.

Ku-Mahamud, K. R., Kasim, M. M., Abd. Ghani, N. F. \& Abdullah, F. (2011). An efficiency analysis of projects using DEA. European Journal of Scientific Research, 52(4), 476-486.

Liu, J. S., Lu, L. Y. Y., Lu, W. M., \& Lin, B. J. Y. (2013). A survey of DEA applications. Omega, 41, 893-902.

Mizala, A., Romanguera, P. \& Farren, D. (2002). The technical efficiency of schools in Chile. Applied Economics, 30, 1089-100.

Monfared, M. A. S., \& Safi, M. (2013). Network DEA: an application to analysis of academic performance. Journal of Industrial Engineering International, 9, 1-10.

Shen, Y., Hermans, E., Ruan, D., Wets, G., Brijs, T. \& Vanhoof, K. (2011). A generalized multiple layer data envelopment analysis model for hierarchical structure assessment: A case study in road safety performance evaluation. Expert Systems with Applications, 38, 1526215272.

Seiford, L. M. and Thrall, R. M. (1990) Recent developments in DEA: The mathematical programming approach to frontier analysis. Journal of Econometrics, 46, 7-38.

Tone, K. \&Tsutsui, M. (2009). Network DEA: A slack -based measure approach. European Journal of Operational Research, 197, 243- 252.

Tumuti, W., Wanderi, P. M., \& Lang 'at -Thoruwa, C. (2013). Benefits of university-industry partnerships: The case of Kenyatta university and equity bank. International Journal of Business and Social Science, 4, 17-28.

Wan Husain, W.R. (2012). Comparative evaluation of public universities in Malaysia using data envelopment analysis (Unpublished doctoral dissertation). University of Warwick School of Business.

Worthington, A. (1999). Performance indicators and efficiency measurement in public libraries. Australian Economic Review, 32(1), 31-42.

Yu, C. (1998). The effects of exogenous variables in efficiency measurement: A Monte Carlo study, European Journal of Operational Research, 105, 569-80. 